\title{
Integrating the Mechanical Engineering Curriculum Using a Long-term Green Design Project - The Planetary Gearset
}

\section{Dr. Eric Constans, Rowan University}

Eric Constans is an Associate Professor in Mechanical Engineering at Rowan University. His research interests include engineering education, mechanical design and acoustics and vibration.

\section{Shivakumar I Ranganathan, Rowan University}

Dr. Shivakumar Ranganathan is an Assistant Professor in the Department of Mechanical Engineering at Rowan University, Glassboro, NJ. He earned a $\mathrm{PhD}$ in mechanical engineering from the University of Illinois at Urbana-Champaign. He was then a post-doctoral fellow in the Department of Nanomedicine and Biomedical Engineering at the University of Texas Medical School at Houston. Prior to starting his $\mathrm{PhD}$, he worked as a mechanical engineer at General Electric (GE) Global Research. He has won several awards, including the University Gold Medal during his undergraduate studies, the Hats-Off Award and Management Award for outstanding research contributions at GE, and more recently the certificate of recognition awarded by Shell for for exceptional work in the design, fabrication and testing of the EcoStallion prototype vehicle. His research interests span a variety of topics in multiscale computational mechanics, mesoscale heat conduction, engineering education, biomechanics and biomaterials.

\section{Prof. Wei Xue, Rowan University}

Dr. Wei Xue is currently an assistant professor in the Department of Mechanical Engineering at Rowan University. He received his B.S. and M.S. degrees in electrical engineering from Shandong University, China, and the Ph.D. degree in mechanical engineering from the University of Minnesota, Twin Cities. 


\title{
Integrating the Mechanical Engineering Curriculum Using a Long-term Green Design Project - The Planetary Gearset
}

\begin{abstract}
Students at the Rowan University department of Mechanical Engineering have been assigned a long-term, large-scale design/build project in order to study the effects of integrating the curriculum on subject matter retention and design efficacy. The project, a bench-scale hybrid electric powertrain system, is designed, analyzed and fabricated by students in six modules, starting in their sophomore year and culminating in their final semester as seniors. This complex project has been selected in order to integrate the core mechanical engineering courses: Mechanical Design, Thermodynamics, System Dynamics and Control, and Fluid Mechanics. A bench-scale hybrid-electric vehicle powertrain has sufficient complexity to involve all Mechanical Engineering disciplines and the simplicity to be built by students over the course of five semesters. The research is designed to test two hypotheses:
\end{abstract}

1. A long-term design project that integrates knowledge from multiple courses strengthens student knowledge retention.

2. A large-scale design project requiring tools from many courses improves student problem-solving and design skills.

By integrating five semesters of the mechanical engineering curriculum into a cohesive whole, this project has the potential to transform the way undergraduate education is delivered. Before and after testing is being conducted to assess: a) Change in retention between courses and b) Change in student problem-solving and design skills.

The centerpiece of the hybrid powertrain is the planetary gearset, which combines power from the air engine and electric motor to produce the desired output speed at the wheels. During the fall semester of their Junior year, the students design and fabricate a small planetary gearset, and conduct tests to assess its performance. The planetary gearset project is conducted in Machine Design, a core mechanical engineering course. This paper describes the planetary gearset assignment only - a description of the full hybrid powertrain project is given the papers listed in the References. Based on student feedback, an overwhelming majority of the students felt that the "hands on" project was valuable in the Machine Design course and enjoyed working on the project. 


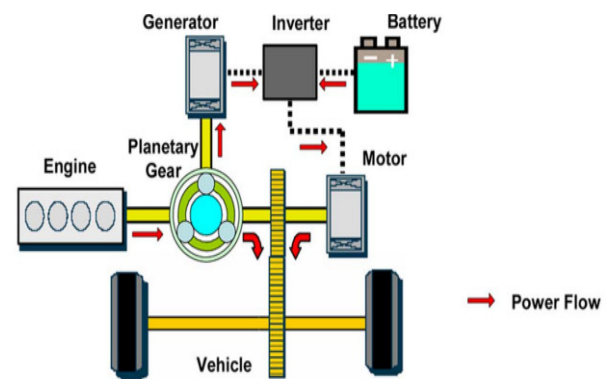

Figure 1: Schematic diagram of the Toyota Hybrid System showing the major components. Students at Rowan University design and build a bench-scale version of this powertrain over the course of five semesters.

\section{Introduction}

One of the most exciting innovations in automotive technology is the development and realization of the hybrid-electric powertrain. The most commercially successful hybrid vehicle has been the Toyota Prius; a schematic diagram of the Toyota Hybrid System is shown in Figure $1[1]$.

Students at Rowan University design and fabricate a bench-scale version of the THS over the course of five semesters, as a way of integrating the Mechanical Engineering curriculum. Parts of this project have been described in earlier papers, [2], [3], [4] and only a short background will be given here. A wealth of information about the project is available on the author's website www.benchtophybrid.com. See the "Planetary Gearsets" tab for further information on the project discussed in this paper.

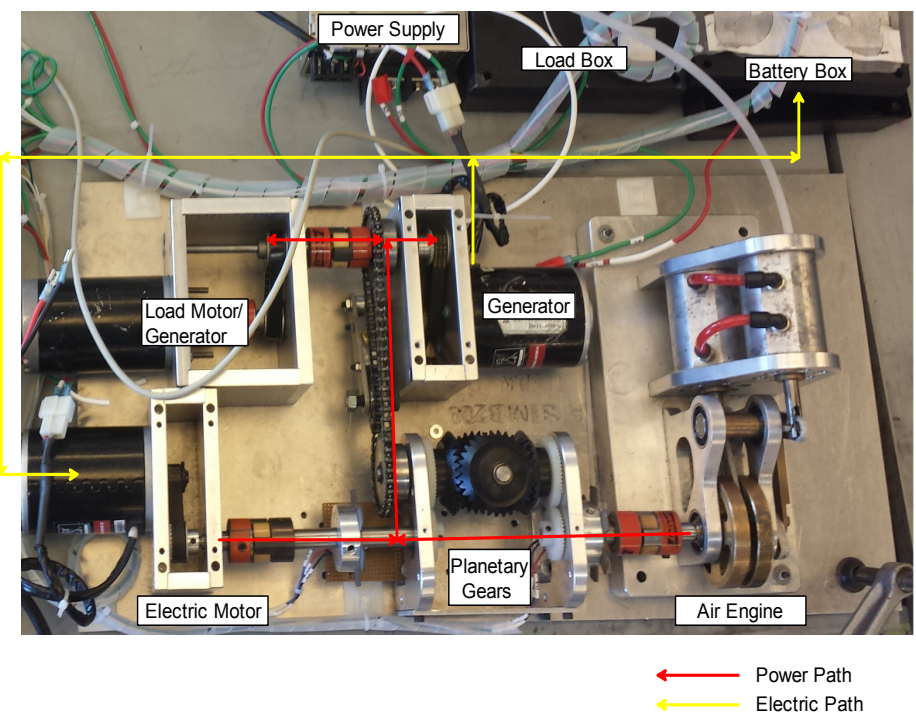

Figure 2: Bench-scale Hybrid Power Train prototype

Figure 2 depicts the "faculty prototype" of the bench-scale hybrid powertrain that students in our program build. The main difference between the bench-scale version and the THS is that an air engine is used instead of a gasoline-powered engine as the prime mover [5]. The flow of air to the engine is controlled by solenoid valves (not shown). Also, the prototype has a DC electric 
motor and DC generator so there is no need for an inverter. The centerpiece of the hybrid system is the planetary gearset, which is the subject of this paper.

Many instructors have described using planetary gearsets as teaching tools in their classrooms [6], [7], [8] but the authors have found no mention in the literature of a planetary gearset used in a design/build project. Students were given the planetary gearset project during the fall semester of their Junior year in their Machine Design course. Earlier in the semester they designed and fabricated air engines in their Thermal-Fluid Sciences course. By the end of this semester, each student team had completed the hardware necessary for fabricating a complete hybrid power train; the control system is left to the System Dynamics and Control course during their Senior year.

\section{Background: Planetary Gearsets}

The most common type of planetary gearset is shown in Figure 3. It consists of four major components: the sun, one or more planets, a ring gear and a carrier (often called the arm or the spider). The major difference between planetary gearsets and ordinary gearsets is that the planets "orbit" the sun; that is, their shafts are not fixed in space. It is this epicyclic motion that permits such interesting behavior.
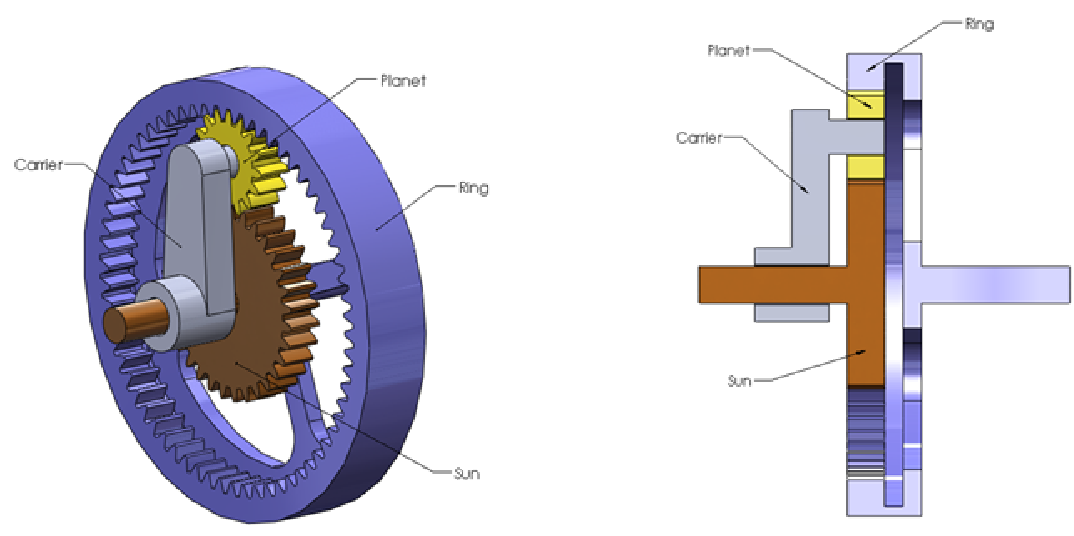

Figure 3: Typical planetary gearset consisting of sun, planets, ring and carrier.

Like all planetary gearsets, the gearset above has two inputs and one output. We may freely choose which shafts are the inputs and which is the output, as shown in Table 1.

Table 1: Possible inputs and outputs from the planetary gearset above

\begin{tabular}{|ccc|}
\hline Option & Inputs & Output \\
\hline $\mathbf{1}$ & sun and carrier & ring \\
\hline $\mathbf{2}$ & ring and sun & carrier \\
\hline $\mathbf{3}$ & ring and carrier & sun \\
\hline
\end{tabular}




\section{Types of Planetary Gearsets}

Zoltan Levai [9] described a total of 34 different types of planetary gearsets that can be constructed; of these only a few are used in practice. A few of the more common ones are shown in Norton [10], but the most widespread are the sun/planets/ring shown in Figure 3 and the differential shown in Figure 4. Animations for the twelve types shown in Norton are given on the author's website www.benchtophybrid.com in the "Planetary Oddities" section.

The differential, shown in Figure 4, differs from most gearsets in that it is composed of miter gears rather than spur (or helical) gears. The "sun" gears are those that do not undergo the epicyclic motion experienced by the planets. The differential is a natural fit for the bench-scale hybrid project because the two input speeds are similar in magnitude.

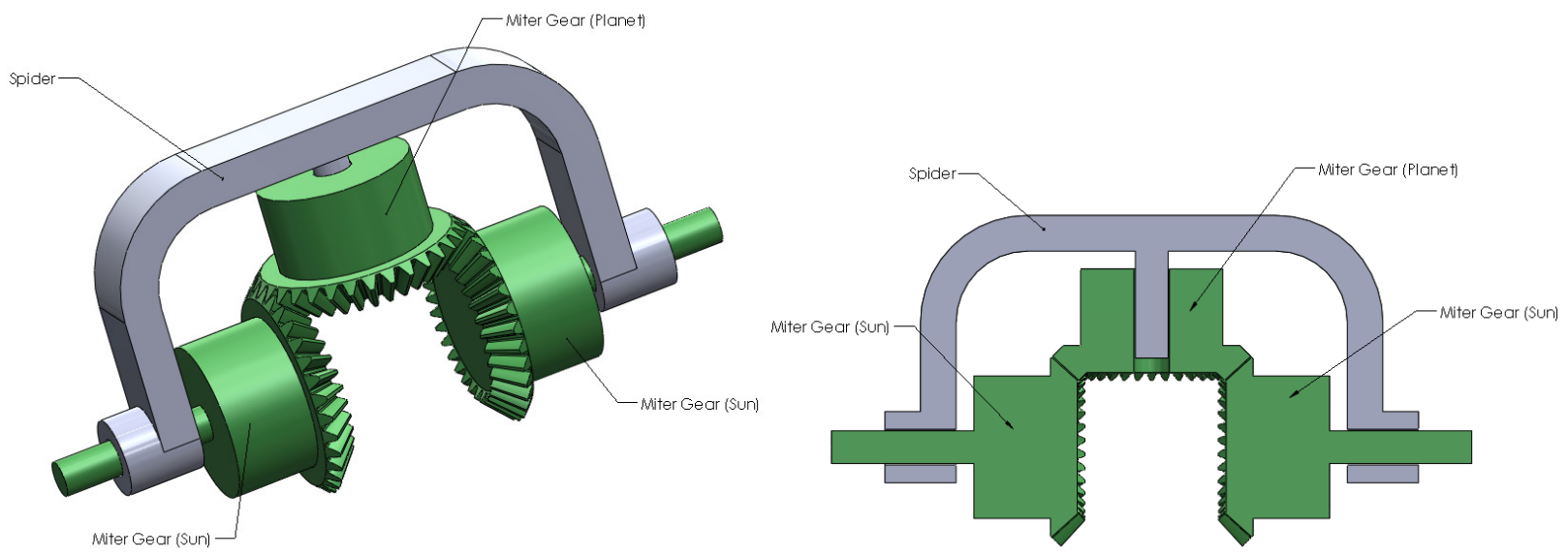

Figure 4: Differential gearset, one of the most commonly seen planetary types

\section{Analysis of Planetary Gearsets}

Planetary gearsets sometimes behave in counterintuitive ways, but we can develop a few simple formulas which apply to any gearset, no matter how complicated. To begin the analysis, imagine for the moment that we hold the arm fixed. Define the basic ratio, $b$, as

$$
b=\frac{\text { speed of faster input shaft }}{\text { speed of slower input shaft }} \text { (with the arm held fixed) }
$$

While it is possible for the basic ratio to be positive or negative, its magnitude must always be greater than or equal to 1 , since we have defined it as the ratio of the faster speed to the slower. Thus

$$
|b| \geq 1
$$

by definition. In the preceding analysis we held the arm fixed, but the behavior of the input and output gears relative to the arm must hold no matter what the arm does. That is, rotation of the arm (and revolution of the planets) does not affect the ratio between sun and ring, since this ratio is determined by the numbers of teeth in each gear. Let us now repeat the preceding analysis, but 
this time allow the arm to rotate. Define $\varphi_{f}$ as the rotational speed of the faster gear relative to the arm. That is

$$
\varphi_{f}=\omega_{f}-\omega_{a}
$$

where the $\omega_{f}$ and $\omega_{a}$ give the rotational speed (relative to ground) of the faster gear and arm, respectively. Also, define the $\varphi_{s}$ as the rotational speed of the slower gear relative to the arm

$$
\varphi_{s}=\omega_{s}-\omega_{a}
$$

Since the relationship of the two gears must remain even if the arm rotates, we can write

$$
b=\frac{\varphi_{f}}{\varphi_{s}}=\frac{\omega_{f}-\omega_{a}}{\omega_{s}-\omega_{a}}
$$

Rearrange the equation above to obtain

$$
\omega_{f}-\omega_{a}-b\left(\omega_{s}-\omega_{a}\right)=0
$$

This is the general kinematic equation for a planetary gearset. We can use it to find the speed ratios for any planetary gearset, provided we have obtained the basic ratio in advance. If we know the speeds of the two input shafts, we can use the equation to solve for the output speed.

$$
\begin{aligned}
\omega_{f} & =\omega_{a}(1-b)+b \omega_{s} \\
\omega_{s} & =\frac{1}{b}\left[\omega_{f}+\omega_{a}(b-1)\right] \\
\omega_{a} & =\frac{\omega_{f}-b \omega_{s}}{1-b}
\end{aligned}
$$

\section{Efficiency in Planetary Gearsets}

Once the speed ratios of a given planetary gearset are known, the designer must determine the efficiency of the gearset. Planetary gearsets can be designed with efficiencies greater than those of the individual gears within the set, but (if the designer is not careful) can also be designed with such low efficiency as to be unusable. The method presented here is based upon that given by Molian [11], and is presented in much more detail on the project website.

The first step in calculating the overall efficiency is to hold the arm fixed, and calculate the basic efficiency, $E_{0}$ of the gearset, using the chart given by Molian. This basic efficiency must be modified to account for motion of the arm. We begin by noting that all power losses due to friction occur because of motion relative to the arm in the gearset; that is, frictional losses can only occur when gear teeth are rubbing against each other. If we were to rotate the entire gearset as a rigid unit, the power loss would be zero, since the gear teeth would not be coming into and out of mesh with each other.

In other words, power losses due to friction can only occur when the relative velocities in Equation (3) and (4) are nonzero. Rotating the entire gearset as a rigid body would make 


$$
\omega_{f}=\omega_{s}=\omega_{a}
$$

which would make

$$
\varphi_{f}=\varphi_{s}=0
$$

Thus, all frictional power losses are proportional to the relative angular velocities, $\varphi_{f}$ and $\varphi_{s}$, and not the absolute angular velocities, $\omega_{f}, \omega_{s}$ and $\omega_{a}$.

\section{Power Balance in the Planetary Gearset}

The power transmitted by a shaft is the product of its torque and angular velocity:

$$
P=T \omega
$$

For static equilibrium, the sum of the torques coming into the gearbox must equal zero:

$$
T_{f}+T_{s}+T_{a}=0
$$

In the expression above, it is clear that not all torques can be positive (or negative). If the torque on a shaft has the same sign as its angular velocity, then we infer that the shaft is being driven, usually by a motor. Conversely, if the torque has the opposite sign as the angular velocity, we assume that the shaft is driving a load. Conservation of energy dictates that the power leaving the gearbox must be the same as that entering the gearbox (for the moment assuming 100\% efficiency.)

$$
P_{f}+P_{s}+P_{a}=0
$$

Substitute torque and angular velocity for each shaft:

$$
T_{f} \omega_{f}+T_{s} \omega_{s}+T_{a} \omega_{a}=0
$$

But power losses are only proportional to the relative angular velocities, so that

$$
T_{f} \varphi_{f}+T_{s} \varphi_{s}+\left(T_{f}+T_{s}+T_{a}\right) \omega_{a}=0
$$

but the sum of all three torques is zero, thus

$$
T_{f} \varphi_{f}+T_{s} \varphi_{s}=0
$$

The first term in the expression above is the power consumed by the faster shaft, and the second gives the power consumed by the slower shaft. Up to now we have assumed $100 \%$ efficiency in the geartrain. To make the analysis realistic, we must define two cases:

1. Power enters through fast shaft: $\quad E_{0} T_{f} \varphi_{f}+T_{s} \varphi_{s}=0$ 
2. Power enters through slow shaft: $\quad T_{f} \varphi_{f}+E_{0} T_{s} \varphi_{s}=0$

In each expression, only a fraction of the power from the driving shaft is available to the driven shaft. The definition of overall efficiency is

$$
E=\left|\frac{P_{\text {out }}}{P_{\text {in }}}\right|=\left|\frac{T_{\text {out }} \omega_{\text {out }}}{T_{\text {in }} \omega_{\text {in }}}\right|
$$

A much more thorough explanation of planetary gearset efficiency can be found on www.benchtophybrid.com in the Planetary Gearset section. It was necessary for students to calculate the efficiency of their proposed gearsets before construction in order to ensure adequate performance.

\section{The Assignment}

The students completed this design project in Machine Design, a required Junior level course. They worked in groups of three, and there were 60 students in two sections. The objective of the design project was to design, build, and test a planetary gearset that combined two inputs into one output. At the end of this project, students were expected to deliver a functional planetary gearset that could be combined with other machine components for the hybrid powertrain.

\section{Design Requirements}

- Students work in teams, with 3 students in each team.

- Each team designed and built the planetary gearset and necessary fixtures.

- 2 inputs: one came from electric motor, speed range 0-2000 rpm; the other air motor, speed $1000 \mathrm{rpm}$.

- 1 output: $500 \mathrm{rpm}$ to a chain sprocket (2737T171 from McMaster-Carr)

- Input and output shafts were $1 / 2$ " in diameter, 2.7 " (on center) above the base

- Designs were reviewed by instructors and machine shop technicians before construction began.

- Gears and bearings were ordered from the following websites

- SDP/SI: www.sdp-si.com

○ McMaster-Carr: http://www.mcmaster.com/

\section{Documentation Requirements}

At the end of the project, each team submitted the following documentation:

- A YouTube video (up to $5 \mathrm{~min}$ ) that explained the gearset design and showed it in operation.

- A short report showing the calculation steps to obtain speed ratio and efficiency of the gearset.

- 3D drawings of the CAD models (in SolidWorks) were also included in the report.

\section{Project Grading}

The project was worth $15 \%$ of the final grade in Machine Design. It was graded upon:

- The functionality of the gearset $(70 \%)$

- The quality of the design and final device $(30 \%)$

\section{Results and Discussion}

In order to prepare the students for the term project, an in-class assignment was created and assigned that enabled them to better understand the working of planetary gear trains. A prototype of a gearset with sun and planet arrangement was used for this purpose as shown in Figure 5. 


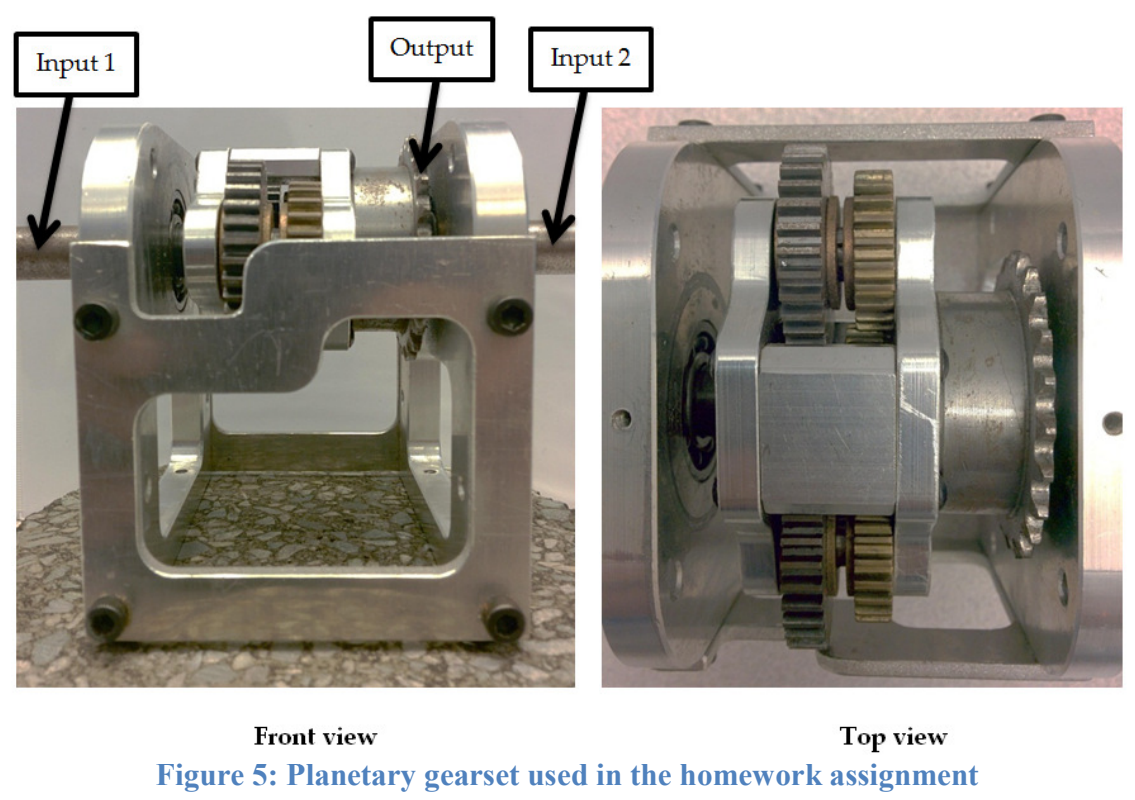

In this assignment, the students were asked to establish a relationship between the two inputs and the output experimentally for various combinations of the input shaft speeds (see Table 2). The students were able to establish the relationship by manually turning the input shafts (using a hand drill) and by observing the number of turns made by the output sprocket. The results obtained were simply scaled appropriately to determine the unknowns in Table 2. Once this exercise was complete, the theoretical background for the analysis of planetary gearsets was introduced to the students. The students were then able to appreciate the mathematical relationship between the two inputs and the output speeds [see Eq. (7)].

Table 2: Possible inputs and outputs from the planetary gearset above

\begin{tabular}{|ccc|}
\hline Input $\mathbf{1}(\mathbf{r p m})$ & Input $\mathbf{2}(\mathbf{r p m})$ & Output (rpm) \\
\hline $\mathbf{0}$ & $100(\mathrm{cw})$ & $? ?$ \\
\hline $\mathbf{1 0 0}(\mathbf{c w})$ & 0 & $? ?$ \\
\hline $\mathbf{1 0 0}(\mathbf{c w})$ & $? ?$ & 0 \\
\hline $\mathbf{?}$ & $100(\mathrm{cw})$ & 0 \\
\hline $\mathbf{1 0 0}(\mathbf{c w})$ & $100(\mathrm{cw})$ & $? ?$ \\
\hline $\mathbf{1 0 0}(\mathbf{c w})$ & $100(\mathrm{ccw})$ & $? ?$ \\
\hline
\end{tabular}

By the end of the project period, each team was able to design and build a functioning planetary gearset. The videos of each team's project can be seen at www.benchtophybrid.com under the Student Videos heading in the Planetary Gearsets tab.

The idea of designing and building a planetary gearset in a course project was well received by students. There was a high level of interest from the students even before the project was officially assigned. The overall student feedback of the project was positive. Many students found the project "challenging" but "fun". The students were particularly enthusiastic during the design process and the final testing. Because the project had a close relationship to automotive technology and mimicked a real-world engineering task, most students were eager to work on the 
gearset designs. A formal survey was conducted after the project for students to provide feedback and comments. Three questions were created to target three areas: content, learning experience, and overall impression. The results of two scale-based questions are summarized in Table 3. Based on the survey results, $96 \%$ of the students felt that the "hands on" project was valuable in the Machine Design course; $80 \%$ of them "enjoyed" working on the project.

Table 3: Survey questions and summary of responses

\begin{tabular}{|cccccc|}
\hline Question & $\begin{array}{c}\text { Strongly } \\
\text { Agree }\end{array}$ & Agree & $\begin{array}{c}\text { Neither Agree } \\
\text { nor Disagree }\end{array}$ & Disagree & $\begin{array}{c}\text { Strongly } \\
\text { Disagree }\end{array}$ \\
\hline $\begin{array}{l}\text { Was the "hands on" project on } \\
\text { gearbox design valuable in the } \\
\text { machine design course? }\end{array}$ & $52 \%$ & $44 \%$ & $4 \%$ & $0 \%$ & $0 \%$ \\
\hline $\begin{array}{c}\text { Did you "ENJOY" working on } \\
\text { the gearbox design? }\end{array}$ & $56 \%$ & $24 \%$ & $16 \%$ & $0 \%$ & $4 \%$ \\
\hline
\end{tabular}

The third question asked students to provide written comments on the project. Some students suggested that the schedule of the project could be improved. Assigning the project earlier in the semester could help them generate ideas and collect information ahead of time, and better prepare themselves for the actual gearset designs. They also raised the concerns on budgeting and physical constraints of the final prototypes. These issues will be addressed in our next offering of the Machine Design course.

Almost all of the students built either the sun/planet/ring configuration or a bevel differential. One interesting exception was provided by the student team led by Carl Kilcoyne, whose design is shown in Figure 6, below. The spur gear differential consisted of six 32-pitch, 20-tooth, 20 degree pressure angle acetyl gears. The six gears were held together using two aluminum plates for the differentials carrier and six aluminum shafts. Two of the six shafts were used to hold the sun gears and acted as the input shafts for the gear set. The other four gears and shafts formed the differential's planetary gears [12].
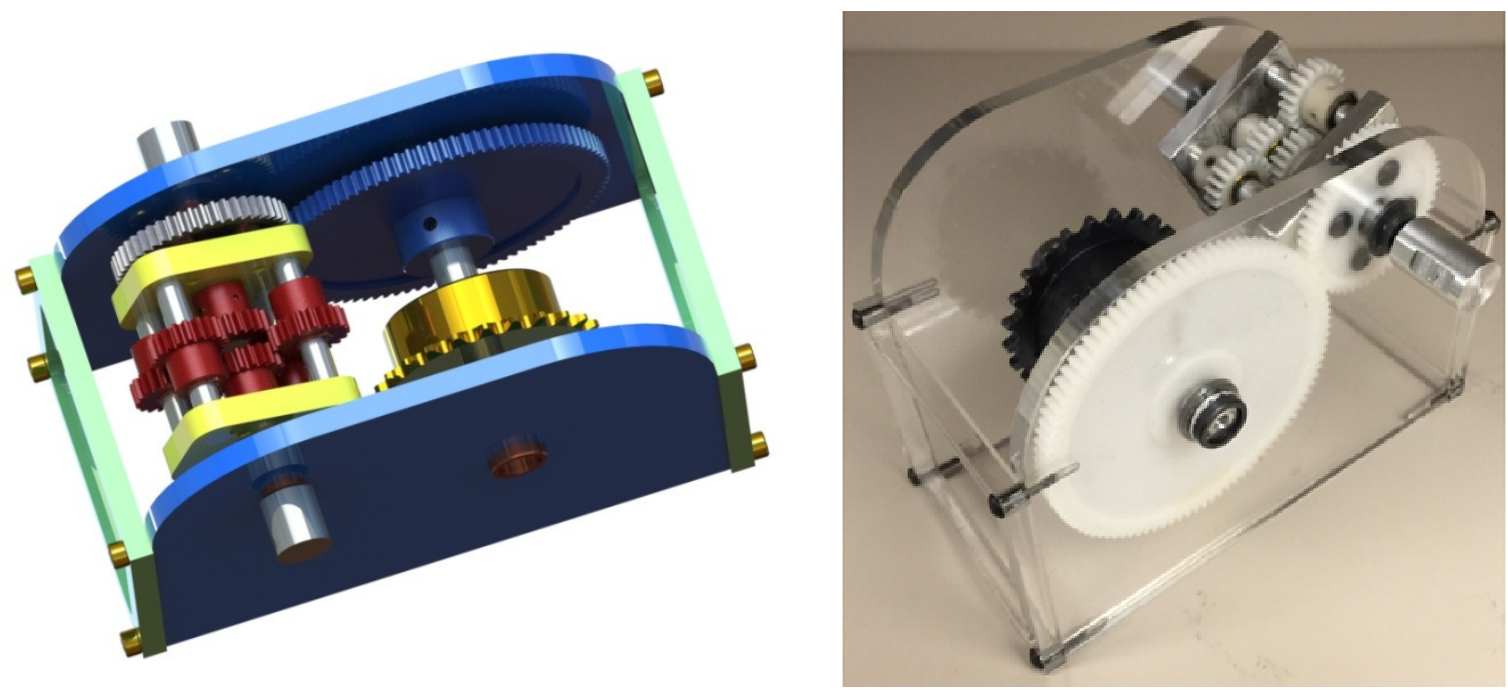

Figure 6: Spur gear differential designed by Carl Kilcoyne, Rowan M.E. student 


\section{Conclusions}

This paper describes the use of a planetary gearset as a design/build project in a Junior-level Machine Design course. 60 students, working in groups of three, completed the project and documented their results on video, and in formal, written reports. Student feedback was very positive in general. Future improvements of the project will be focused on scheduling, budgeting, and clearance of physical constraints. The planetary gearset is the centerpiece of the bench-scale hybrid powertrain, which our students are completing over the course of five semesters. With the successful completion of the planetary gearset, our students are now ready to begin tackling the challenge of developing an overall control strategy for the hybrid system.

\section{Acknowledgements}

The authors wish to acknowledge the support of the NSF-TUES program in the Division of Undergraduate Education, DUE-1044532, which made this research possible. Any opinions, findings, and conclusions or recommendations expressed in this material are those of the authors and do not necessarily reflect the views of the National Science Foundation.

\section{Bibliography}

[1] Toyota Motor Corporation, "Toyota Hybrid Transmission II (THS II)," Toyota Public Affairs Division, Japan, May 2003. [Online]. Available: http://www.evworld.com/library/toyotahs2.pdf. [Accessed 20 February 2013].

[2] E. W. Constans, J. Kadlowec, K. K. Bhatia, H. Zhang, T. Merrill and B. Angelone, "Integrating the Mechanical Engineering Curriculum using a Long-Term Green Design Project: Part 1: The Hybrid Powertrain," ASEE Annual Conference, 2012.

[3] E. W. Constans, M. S. Acosta, K. K. Bhatia, H. Zhang and J. Kadlowec, "Development and Implementation of a Control Strategy for a Hybrid Power Train System in a Classroom Setting," ASEE Annual Conference, 2014.

[4] M. S. Acosta, E. W. Constans, K. K. Bhatia, J. Kadlowec, T. Merrill, H. Zhang and B. Angelone, "Integrating the Curriculum using a Bench-Scale Hybrid Power Train," SAE 2014 World Congress \& Exhibition, 2014.

[5] K. K. Bhatia and E. W. Constans, "Novel Use of an Engine Design Project to Cross-Link Knowledge from Courses in both Mechanical Design and Thermodynamics," Frontiers in Engineering Education, 2006.

[6] H. L. Stalford, "Hands-On Method for Teaching Design of Mechanical Components Course," ASEE Annual Conference, 2014.

[7] G. Liao, "Using Lever Analogy Diagrams in Teaching Compound Planetary Gear Trains," ASEE Annual Conference, 2006.

[8] R. A. Beardsley and C. O. Pringle, "Machine Design Lab: Using Automotive Transmission Examples to Reinforce Understanding of Gear Train Analysis," ASEE Annual Conference , 2011.

[9] Z. Levai, "Structure and Analysis of Planetary Gear Trains," Journal of Mechanisms, vol. 3, pp. 131-148, 1968. 
[10] R. L. Norton, Design of Machinery, New York: McGraw-Hill, 2012.

[11] S. Molian, Mechanism Design: An Introductory Text, Cambridge: Cambridge University Press, 1982.

[12] C. Kilcoyne, K. Ternay, J. Witko, "Gearset", Machine Design final report, Rowan University, 2014. 